\section{STELLAR PHOTOGRAPHY AT HARVARD}

$A T$ the meeting of the Astronomical Society which was held on June 8 last, Prof. Pickering of Harvard College Observatory, so well known for his stellar observations, and who is a Foreign Associate of the Society, attended and gave an interesting account of the work which has been done during the past few years at his observatory.

Some few years ago Prof. Pickering took up the work of determining the intensity of the light of the principal stars by eye observation, without taking the question of colour into consideration, work which has been already dwelt upon in this journal. For this purpose he used a photometer, completing his observations, which number some 90,000, about a year ago, and a large part of his results are already in print. The published results of the more important investigators of star magnitudes, from the time of Almagest and Lûfi, have al=o been reduced. Sir W. Herschel's observations, which appeared almost a century ago in the Philosophical Transactions, have likewise been taken in hand at Harvard Observatory and completely discussed. Sir John Herschel's works, the "Uranometria Nova," the "Durchmusterung," as well as many other works in the same field, have also been made use of in preparing the Harvard Catalogue, which therefore shows those cases in which the photometric observations carried out by Prof. Pickering differ from the results obtained by other observers, when their observations are reduced to the same system. These eye observations of stars having been completed, Prof. Pickering, in conjunction with his brother, Mr. W. H. Pickering, has taken up stellar photography from the same point of view. By this means a comparison is obtained between the brightness of the star as seen by the eye, and its brightness as determined by its greater or less action upon the photographic plate; and by a comparison of photographs taken on different nights any variation in brightness may be detected; whilst the exact positions of stars may of course be more accurately and permanently recorded than by eye observations. Mr. A. A. Common recently, by taking paotographs of the nebula in Orion on different nights and comparing them, has thus Leen able to detect a probable variaiion in one of the stars in the nebula, and in 1858 Professor George P. Bond, by measuring the diameters of stars in photographs was able to determine the relative brightness of the two stars which form the double $\zeta$ Ursæ Majoris.

But the work at Harvard University was to do more than this. The stars which Prof. Bond examined were close together. Prof. Pickering wished to compare stars far removed from each other. For this purpose the ordinary method of stellar photography, by which photographs are taken at the foci of large telescopes, would not suffice. These photc graphs only comprise a small region of but one or two degrees in diameter. A different method was therefore employed in the Harvard observations. A wholly different form to the ordinary equatorial telescope was used. It is not unusual to construct photographic cameras to take pictures of buildings which subtend an angle of $60^{\circ}$ or even $90^{\circ}$. But when applied to the stars, however, the images at the edges are very poor, and only very small apertures can be used. It has, however, been found that some of the best lenses for pictures can be obtained covering a circle of $20^{\circ}$ diameter without serious distortion, and at the same time large apertures can be used, thus reducing the time of exposure. In order to still further this work, Mr. W. H. Pickering investigated the sensitiveness of various photographic plates, and obtained some so sensitive that stars of the fifth and sixth magnitude have been photographed without using clockw ork, they forming dots or making lines, as their images pass across the photographic plate, the length of these lines depending of course upon the time during which the plate is exposed. If the plate be exposed during ten seconds a distinct dot is obtained, whilst an exposure of thirty seconds causes a short line to be formed. The plates used at Harvard Observatory are six by eight inches. They are divided into six equal parts, each part being in turn exposed. By this means six regions of the heavens, each about $15^{\circ}$ square, may be photographed on one plate; and by a variation in the dot and ine system employed, sometimes taking the dot and sometimes the line first, three pictures may be taken on a single division of one of the plates without giving rise to any confusion. Instead of simply six, therefore, eighteen photographs are taken on one of these plates, so that on a single plate a portion of the heavens of more than three hours' right ascension, and extending from $30^{\circ} \mathrm{S}$. to $60^{\circ} \mathrm{N}$, may be included. Since each portion of the plate covers a region of about $15^{\circ}$, the camera mounting has a series of notches or stops, by which it may be instantly moved through that amount either of right ascension or declination.

When photographing the following is the exact method employed. The first exposure takes the region between $30^{\circ}$ and $15^{\circ}$ south declination, and between one hour and a half and half an hour west of the meridian. First the plate is exposed for ten seconds, and each star records itself by a dot. The plate is then covered for ten seconds; next it is exposed for a period of thirty seconds, and each star makes a line on the plate. By means of the clamping arrangement to which we have referred the plate is then moved through one hour in right ascension. This takes up the remaining few seconds of the minute, so that the taking of the next photograph begins with the first second of another minute. The camera is then on the meridian. The same part of the plate is again exposed, and in order to distinguish this series of stars from those first photographed, this time the plate is exposed first during thirty seconds, and then during ten, so that the result is a line followed by a dot. This gives the second series. But the same portion of the plate may be again used. The remaining ten seconds of the second minute, like those of the first, are spent in moving the camera through another hour of right ascension. Then $a^{*}$ fresh exposure is made for thirty seconds, a line simply being obtained without a dot, and this completes the series. The first class of images is in dots and lines, the second in lines and dots, the third is recognised by the presence of lines alone. The thirty seconds which remain of the third minute are employed in exposing a second portion of the plate, and changing the position of the camera, which now takes in the region from $15^{\circ} \mathrm{S}$. to the equator. The same process is then gone through again, three exposures as before being made in three different positions of right ascension. By continuing this process, taking three photographs on each of the six portions into which the plate is divided, the whole region included between the declinations of $-30^{\circ}$ and $+60^{\circ}$, and between three hours of right ascension, $1 \frac{1}{2}$ hours on each side of the meridian, being one eighth of the whole heavens, excluding the circumpolar stars, will be photographed on one plate, the whole operation occupying but eighteen minutes. With regard to those stars in the vicinity of the Pole, some other method will have to be adopted. Thus much for one branch of the work-and an important branch-carried on at Harvard Observatory.

Another portion of their work consists in the preparation of a photographic map of the entire heavens. The method just described, in which clockwork is dispensed with, only enables those stars whose magnitude is not less than five or six to be photographed, and stars of a less magnitude than this must of course be included in a map of the heavens. The camera in this work, therefore, is driven by clockwork. By this means stars of the eighth magnitude record their images on the photographic plate, and as many as 200 are visible in the paper print within a 
circle of $5^{\circ}$ in diameter. A photograph taken in this way of a portion of the constellation of Orion, besides showing the three stars of the Belt and the Sword-Handle, gives an interesting picture of the nebula.

With reference to the question of the colours of stars it is interesting to note the faintness of $a$ Orionis in the photographs. To the eye its brilliancy is almost as great as that of $\beta$, whilst in the photograph it is not more prominent than $\lambda$. The reason is to be found in the colour of $a$. It is a red star, and consequently makes but little impression on the photographic plate.

Again, in the constellation Cetus the three stars which are brightest to the eye are $\alpha, \gamma$, and $\delta$. A, which is the brightest of the three, has close to it a very faint companion, scarcely visible to the naked eye, its magnitude being given as 6.3 , whilst that of $a$ is 277 . This is the appearance of this part of that constellation as seen by the eye. A photograph of this region was taken at Harvard with the result that the small star is seen in the photograph nearly as bright as $a$, it being only three-tenths of a magnitude less. The colour of these stars again explains this, a being of a reddish tint, whilst the small star is of a deep blue colour, and being so the rays which flow from it have a greater influence on the photographic plate. A comparison of the number of stars seen in the photograph of Orion with the number in the photometric catalogue, further illustrates this effect of colour. In that part of this constellation included between $5^{\circ}$ north and $5^{\circ}$ south declination, and $75^{\circ}$ to $90^{\circ}$ of right ascension, sixteen stars were common to photograph and catalogue; a like number, being either too small in magnitude or too red in colour, although catalogued, remain unrecorded on the photographic plate; whilst five others seen in the photograph are not given in the catalogue. A reduction has been made of the results given by the plates of different makers, with the view of ascertaining the value of the deviation. In two of such plates the average deviation was $0^{\circ} 21$ of a magnitude, and in two measurements of the same plate it was found to be $0^{\circ} 07$ of a magnitude.

It is obvious from this account of the work at Harvard that star photography is entering into a new phase, and one which will entirely replace the present system of eye observations, for the reason that, whilst the eye is so variable, photographic plates may now be obtained, doing their work with almost definite wave-lengths of light. The constant record of the plate, must in time therefore be preferred to observation by the variable eye. At the same time as photography advances, if it be considered necessary to obtain photographic star maps to record the observations of the average eye, there will be no difficulty in this being done.

\section{NOTES}

IN accordance with the provisions of the Statutes, the Council of the Royal Society met last Thursday to elect one from among themselves to fill the office of president until the annual election on November 3o. The choice, as had been anticipated, fell upon Prof. Huxley. We believe that this ad interim election has given the greatest satisfaction to all the Fellows of the Society.

WE have received from the Johns Hopkins University, Baltimore, the circular giving the programme for the next academic year and a report on the work of the year that is past. Not only are a great number of subjects included in the programme of this University, but provision is made that the work in each section shall be thoroughly done, and we think the Trustees are to be entirely congratulated upon the progress that is being made. Among the scientific subjects we find physics, chemistry, geology, mineralogy, and biology in all its branches. With the other subjects which the programme sets forth we have here of course little to do, but we must add that we are glad to note under the heading "Philosophy" that the study of psychology is well pro- vided for. Not only are there courses of lectures, but a limited number of the students are provided with seats in the physio logical laboratory, where they may prosecute original research. It is so in all the scientific subjects. The work of the advanced student is arranged with a view of initiating him into the methods of original investigation, which, when he has finished his course of instruction, he is encouraged to carry on. Thus in the physical laboratory, which is under the direction of Prof. Rowland and Dr. Hastings, during the past year original investigations have been carried on in many parts of the subject ; for instance, to name one or two, the concave grating has been used in an attempt to photograph the spectrum, and with it an endeavour has also been made to ascertain the wave-lengths of the lines. The unit of electrical resistance has also been investigated during the past year, and during the coming session an attempt will be made to establish an international unit for such resistance. We notice too, as a feature of the advanced course in physics conducted by Prof. Rowland, that besides the lecture; and laboratory work there are weekly meetings for the discussion of the current literature of the subject. The courses in chemistry, which are under the sole control of Prof. Remsen, are likewise excellent. Besides the ordinary courses in general and analytical chemistry, the programme state; that arrangements will soon be made by which the study of applied chemistry-for example, metallurgy, the chemistry of iron and steel, of dye stuff, of soils and fertilisers-may be taken up by the students. Original research has been a prominent feature in this laboratory also, the results appearing in the American Chemical Fournal. With regard to mineralogy and geology we notice that they are included in the courses on chemistry. The courses on biology are most excellent, general biology, embryology, osteology, and plant analysis being included in the first year's work. In the second year the student takes up mammalian anatomy, animal physiology and histology, and animal morphology. Then when the student desires to take up the study of marine animals, the University provides him with a laboratory by the sea itself. This labora. tory was open last year from May I until September 29, and during that time the development of Thallassema was investigated, studies were made with regard to the origin of the oystershell, the parthenogenesis of the Echini, the development of Tubularia, and other subjects, which want of space alone prevents our mentioning. The results of these investigations are published in "Studies from the Biological Laboratory"; abstracts of two of these researches have also been printed in the Proceedings of the Royal Society, and Dr. E. B. Wilson's paper on the Development of Renilla will appear in the Philosophical Transactions. We might add much more to what we have said concerning the excellent character of the work done at this University, as we do not doubt that the other courses are as well provided for as the more purely scientific subjects to which alone we have referred. The Johns Hopkins University, in fact, although but a new institution, has been founded on a broad basic, giving to the student those opportunities for original work which it is so difficult to obtain elsewhere. We should much like to see such an account of original research done and to be done issuing each year from the laboratories of Oxford and Cambridge.

THE Berlin Academy of Sciences has elected Prof. Simon Newcomb (Washington) and Prof. B. Apthorp Gould (director of Cordova Observatory) as corresponding members.

IN our review of the life of Sir Edward Sabine, which appeared in our issue of last week (p. 219), we stated that he accompanied the expedition which under the conmmand of Capt. James Ross was sent to make a magnetical survey of the Antarctic regions. This was an error, as although all the observations 